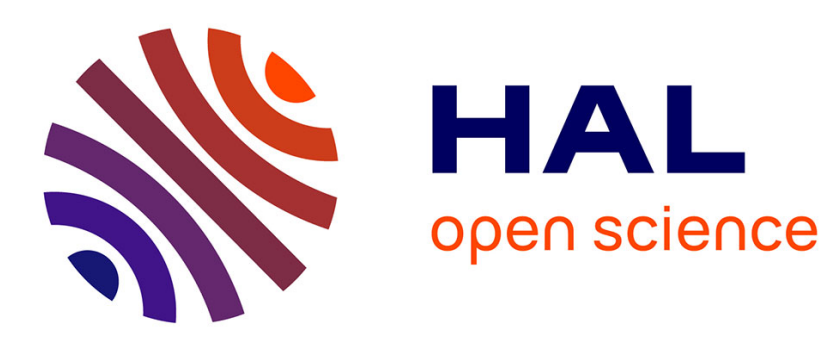

\title{
Impact of the chemical description on a Large Eddy Simulation of a lean partially premixed swirled flame
}

Benedetta Franzelli, Eleonore Riber, Bénédicte Cuenot

\section{To cite this version:}

Benedetta Franzelli, Eleonore Riber, Bénédicte Cuenot. Impact of the chemical description on a Large Eddy Simulation of a lean partially premixed swirled flame. Comptes Rendus Mécanique, 2013, 341 (1-2), pp.247-256. 10.1016/j.crme.2012.11.007 . hal-01272944

\section{HAL Id: hal-01272944 \\ https://hal.science/hal-01272944}

Submitted on $20 \mathrm{Jul} 2017$

HAL is a multi-disciplinary open access archive for the deposit and dissemination of scientific research documents, whether they are published or not. The documents may come from teaching and research institutions in France or abroad, or from public or private research centers.
L'archive ouverte pluridisciplinaire HAL, est destinée au dépôt et à la diffusion de documents scientifiques de niveau recherche, publiés ou non, émanant des établissements d'enseignement et de recherche français ou étrangers, des laboratoires publics ou privés. 


\title{
Impact of the chemical description on a Large Eddy Simulation of a lean partially premixed swirled flame.
}

\author{
Benedetta Franzelli ${ }^{a}$, Eleonore Riber ${ }^{\mathrm{a}}$ and Bénédicte Cuenot $^{\mathrm{a}}$ \\ ${ }^{a}$ CERFACS, CFD Team, 42 Avenue G. Coriolis, 31057 Toulouse Cedex 01, France \\ Received ****; accepted after revision +++++ \\ Presented by B. Franzelli
}

\begin{abstract}
Six different chemical reduced mechanisms are used in a Large Eddy Simulation of a lean partially premixed swirled methane/air flame in order to investigate their capability to describe the flame structure and the species concentrations comprising the pollutant $\mathrm{CO}$ species. The mechanisms range from a two-step fitted mechanism to an analytical scheme composed by 13 species and 73 reactions. Following the classical approach, the performances of the mechanisms have been preliminary analyzed on laminar unstrained free flames. In addition, results for strained premixed counterflow flames have been discussed in order to evaluate their response to turbulence in a very simple way. This work demonstrates that the capability of a mechanism to describe three-dimensional complex turbulent premixed flames could be estimated on results for laminar one-dimensional unstrained and strained flames.

\section{Résumé}

Impact du modèle cinétique dans une Simulation aux Grandes Echelles d'une flamme méthane-air swirlée en régime partiellement prémélangé pauvre.

Six cinétiques chimiques réduites sont utilisées pour le calcul d'une flamme swirlée en régime partiellement prémélangé pauvre avec l'approche de Simulation aux Grandes Echelles afin d'évaluer leur capacité à décrire la structure de flamme et la composition chimique, y compris l'espèce polluante $C O$. Les mécanismes cinétiques testés diffèrent par leur complexité, le plus simple étant un mécanisme global à deux étapes, le plus complexe étant un schéma analytique comprenant 13 espèces et 73 réactions. Pour évaluer leurs performances, les mécanismes sont tout d'abord testés classiquement dans des flammes laminaires prémélangées non étirées se propageant librement. Puis, des calculs de flammes laminaires prémélangées étirées à countre-courant sont analysés pour évaluer simplement la réponse des différents schémas à la turbulence. Ce travail montre que la capacité d'un mécanisme à décrire correctement une flamme turbulente prémélangée dans une configuration complexe peut être anticipée en analysant les réponses du mécanisme dans des flammes prémélangées laminaires non étirées et étirées.
\end{abstract}

Key words: chemical description; partially premixed swirled flame ; response to stretch

Mots-clés : cinétique chimique; flamme swirlée prémélangée ; réponse à l'étirement

$\begin{array}{lllll}\text { Article } & \text { submitted } & \text { to } & \text { 3rd } & \text { INCA }\end{array}$




\section{Introduction}

A growing need for simulations based on reliable chemistries has been underlined in the last years [1] since restrictions on pollutant emissions motivate request for more accurate results. Detailed kinetic mechanisms, comprising hundreds of species and thousands of reactions, correctly predict multiple aspects of flames over a wide range of cases (i.e. one-dimensional flame structure, gas composition in a stirred reactor, ignition delay, etc...) and are available for most hydrocarbons [2]. Unfortunately, using them to simulate turbulent reacting flows in complex geometries is still prohibitive mainly due to their computational cost. On the one side, the computational time drastically increases with the number of species to be solved; on the other side, complex schemes are usually very stiff and demand specific (implicit) algorithms to avoid unreasonably small time steps.

Two approaches have been proposed to overcome this problem: reduced chemistry $[3,4,5]$ where a detailed mechanism is simplified in order to obtain an accurate chemical behavior using fewer species and reactions, and tabulated chemistry $[6,7,8]$ which is based on the idea that information from academic laminar configurations could be stored into a table and used for turbulent calculations. Using tabulation method is still difficult in complex configurations since determining the prototype flame to create the table can be a complicated task if the combustion regime is unknown. For this reason, only reduced chemistries are considered in this work. Two families could be distinguished: fitted schemes and analytical mechanisms. Fitted schemes are characterized by reaction parameters which have been fitted to capture some global quantities such as flame speed or burnt gas state. Analytical mechanisms are systematically derived from detailed or skeletal schemes to include more details on the flame providing a physical insight into the chemical processes. Schemes belonging to the first family are generally easier to develop and implement into a CFD solver compared to the second family's mechanisms. These simplified chemical descriptions should be carefully used when simulating three-dimensional turbulent complex flames since some pieces of information are neglected to reduce the computational cost possibly affecting the accuracy $[9,10]$. Moreover, all these reductions have been developed for laminar configurations and their impact on turbulent unsteady flames has not been completely evaluated [11].

The objective of this work is to identify the characteristics of a reduced mechanism mostly impacting the LES of realistic turbulent premixed flames in order to build from one-dimensional tests a reliable reduced scheme for three-dimensional turbulent configurations or select in a priori way the mechanism offering the best compromise between CPU cost and result accuracy. Six chemical mechanisms for methane/air flames are tested in this work with increasing complexity (Section 2.1): the two-step fitted schemes 2S_CH4_BFER [12] and 2S_CH4_BFER*, the four-step fitted JONES mechanism [13] and the analytical schemes PETERS [14], SESHADRI $[15,16]$ and LU $[17,18]$. Following the classical approach, their performances on laminar premixed freely propagating flames are first discussed in Section 2.2 in terms of flame speed, burnt gas temperature and species profiles. Turbulence mainly interacting with the flame by straining and wrinkling its front, the response of the mechanisms to strain is analyzed in strained premixed counterflow flames to evaluate their response to turbulence in a very simple way (Section 2.3). Once the performances of the mechanisms have been discussed on laminar configurations, their behavior is evaluated on Large Eddy Simulation of the experimental partially premixed swirled burner named PRECCINSTA [19] (Section 3) to verify the impact of the mechanism characteristics identified on the laminar cases.

Email addresses: franzell@cerfacs.fr (Benedetta Franzelli), riber@cerfacs.fr (Eleonore Riber), cuenot@cerfacs.fr (Bénédicte Cuenot). 


\section{Reduced chemical mechanisms}

\subsection{Main characteristics of the six mechanisms}

The six mechanisms are described in the following in order of increasing complexity.

The simplest scheme is the two-step 2S_CH4_BFER mechanism [12] developed following the methodology described in [20]. It accounts for six species $\left(\mathrm{CH}_{4}, \mathrm{O}_{2}, \mathrm{CO}_{2}, \mathrm{CO}, \mathrm{H}_{2} \mathrm{O}\right.$ et $\left.\mathrm{N}_{2}\right)$ and two reactions, the methane oxidation and the $\mathrm{CO}-\mathrm{CO}_{2}$ equilibrium. Both reactions follow an Arrhenius law and unity Lewis numbers are assumed for all species (Table 1). This scheme correctly predicts the flame speed for laminar free flames on a wide range of fresh gas temperature (300 K $\left.<T_{f}<700 \mathrm{~K}\right)$, pressure $(1 \mathrm{~atm}<P<10 \mathrm{~atm})$ and equivalence ratio $(0.6 \leq \phi \leq 1.5)$ as well as the burnt gas temperature for $\phi<1.4$.

The 2S_CH4_BFER scheme does not respond well to strain as it will be discussed in Section 2.3. Therefore, a modified version $\left(2 \mathrm{~S} \_\mathrm{CH} 4 \_B F E R^{*}\right)$ is proposed here to correct its beahvior. In the 2S_CH4_BFER scheme, the species Lewis numbers are modified to $L e_{k}=1.65$ since the flame response to strain is strongly affected by species Lewis numbers [21]. Moreover, the pre-exponential factor for the methane oxidation reaction of the original version has been adjusted multiplying it by a factor 0.8 to correctly reproduce the flame speed for laminar unstrained flames.

The JONES scheme [13] is slightly more complex, comprising seven species $\left(\mathrm{CH}_{4}, \mathrm{O}_{2}, \mathrm{CO}_{2}, \mathrm{CO}, \mathrm{H}_{2} \mathrm{O}\right.$, $\mathrm{H}_{2}$ et $\mathrm{N}_{2}$ ) and accounting for four reactions. Each reaction follows an Arrhenius law whose parameters have been chosen in order to correctly describe the flame structure of both premixed and diffusion flames at ambient temperature $\left(T_{f}=300 \mathrm{~K}\right)$ and atmospheric pressure.

The analytical PETERS mechanism [14] accounts for eight species $\left(\mathrm{CH}_{4}, \mathrm{O}_{2}, \mathrm{CO}_{2}, \mathrm{CO}, \mathrm{H}_{2} \mathrm{O}, \mathrm{N}_{2}, \mathrm{H}_{2}\right.$ and $H$ ) and four reactions. It has been systematically derived on a skeletal mechanism for lean methane/air flames composed of 18 reactions and 13 species. This mechanism has been tested on laminar premixed and diffusion flames at ambient temperature and atmospheric pressure.

The SESHADRI scheme is an improved version of the PETERS scheme proposed by Seshadri and Peters $[15,16]$ by using a computer program for optimization and reduction of detailed mechanisms. It takes into account the same species and reactions as the PETERS mechanism but the global reaction rates are based on a reduction of a more complex skeletal mechanism composed of 25 reactions.

The LU mechanism $[17,18]$ is the most complex reduced mechanism analyzed in this work. It takes into account 13 resolved species $\left(\mathrm{CH}_{4}, \mathrm{O}_{2}, \mathrm{CO}_{2}, \mathrm{CO}, \mathrm{H}_{2} \mathrm{O}, \mathrm{N}_{2}, \mathrm{H}_{2}, \mathrm{H}, \mathrm{OH}, \mathrm{O}, \mathrm{HO}_{2}, \mathrm{CH}_{3}\right.$ and $\left.\mathrm{CH}_{2} \mathrm{O}\right)$ and 73 elementary reactions. It has been derived from the detailed mechanism GRI1.2 applying the directed relation graph method, the sensitivity analysis and the computational singular perturbation approach. This scheme shows a satisfactory behavior on lean premixed methane/air flames, perfectly stirred reactor for $T_{f}=300 \mathrm{~K}$ and auto-ignition configurations from $1000 \mathrm{~K}$ to $1800 \mathrm{~K}$ at atmospheric pressure.

Simplified transport properties are used for all reduced mechanisms: the Prandtl number is assumed constant $(\operatorname{Pr}=0.7)$ whereas the Lewis numbers are assumed constant but not equal for each species except for the two two-step schemes (Table 1). The molecular viscosity $\mu$ follows a power law in temperature $\mu=\mu_{0}\left(T / T_{0}\right)^{\alpha}$, where $\alpha=0.6759$ is the power law constant, $T_{0}=300 \mathrm{~K}$ is the reference temperature and $\mu_{0}=1.8405 \times 10^{-5} \mathrm{~kg} / \mathrm{m} / \mathrm{s}$ is the reference dynamic viscosity. This set of parameters enables to fit the dependence on temperature over the whole range of temperature considered in this work.

The performances of the six chemical mechanisms are compared for laminar premixed freely propagating (Section 2.2) and counterflow flames (Section 2.3) to results obtained using the detailed GRI3.0 mechanism [22] chosen as reference. It is a compilation of 325 elementary chemical reactions and associated rate coefficient expressions, thermochemical parameters and complex transport properties for 
the 53 species involved in them. Results correspond to the operating point of the PRECCINSTA burner, i.e. initial temperature $T_{f}=320 \mathrm{~K}$, atmospheric pressure and global equivalence ratio $\phi=0.83$. All calculations presented in this section have been performed with CANTERA [23].

\subsection{Results on premixed freely propagating flames}

Figure 1a. shows the flame speed obtained with the reduced schemes together with results of the detailed GRI3.0 mechanism over the whole range of flammability at initial temperature $T_{f}=320 \mathrm{~K}$ and atmospheric pressure. For lean and stoichiometric mixtures, all mechanisms correctly reproduce the flame speed. For rich mixtures, the decrease in flame speed is well predicted by all mechanisms except the JONES and PETERS schemes which greatly overpredict it. However, for the composition of interest $(\phi=0.83)$, the agreement with the detailed GRI3.0 scheme is satisfactory for all mechanisms and the largest error (about 15\%) is found for the SESHADRI scheme.

The same comparison is displayed in Fig. 1b. for the burnt gas temperature. The agreement with the GRI3.0 reference scheme is satisfactory for all the mechanisms except the two two-step schemes which overestimate the burnt gas temperature for very rich flames $(\phi>1.4)$. The introduction of additional species in the JONES and the analytical mechanisms enables to improve the description of the burnt gas temperature. Discrepancies are detected for near-stoichiometric mixtures except for the most complex reduced LU scheme which is the only one to correctly predict the burnt gas temperature on the whole range of equivalence ratio. The error on the burnt gas temperature at $\phi=0.83$ is less than $1 \%$ for all the schemes.

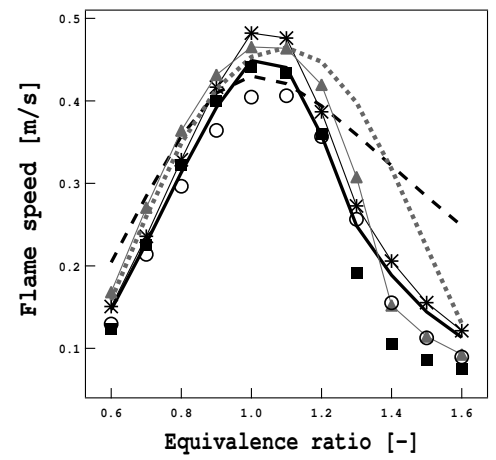

a.

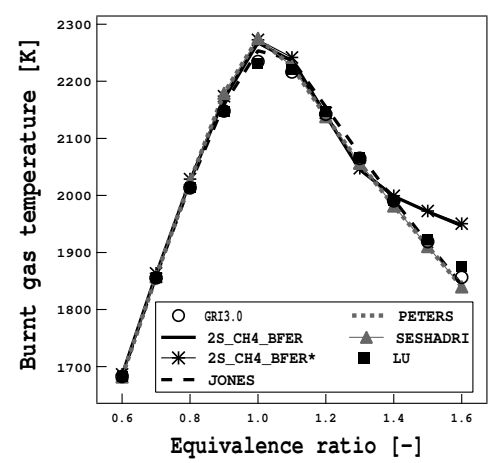

b.

Figure 1. Laminar a) flame speed and b) burnt gas temperature for premixed unstrained methane/air flames at initial temperature $T_{f}=320 \mathrm{~K}$ and atmospheric pressure. Comparison between the reduced mechanisms and the GRI3.0 detailed scheme.

Spatial profiles of $\mathrm{CH}_{4}, \mathrm{CO}_{2}$ and $\mathrm{CO}$ species representing respectively reactants, products and intermediate species for the reduced schemes are compared to the GRI3.0 scheme at $\phi=0.83, T_{f}=320 \mathrm{~K}$ and $P=1 \mathrm{~atm}$ in Fig. 2. It has been chosen to zoom in the reaction zone where the main discrepancies occur. Therefore the equilibrium state can not be evaluated from Fig. 2 but it has been verified that it is correctly described by all schemes. The $\mathrm{CO}_{2}$ spatial profile predicted by the GRI3.0 scheme shows two different zones: a first reaction zone characterized by a high gradient, and a second post-flame zone where recombination takes place and $\mathrm{CO}_{2}$ increases slowly. This structure is not captured by the two-step mechanisms which are not able to reproduce the slower recombination zone and reach equilibrium too quickly. The JONES scheme shows good agreement with the detailed mechanism but better results are obtained with all analytical mechanisms.

A correct description of the $\mathrm{CO}$ concentration is necessary to predict pollutants but reproducing the maximum value of $C O$ species is a hard task since it is first produced in the reaction zone and then oxidized 

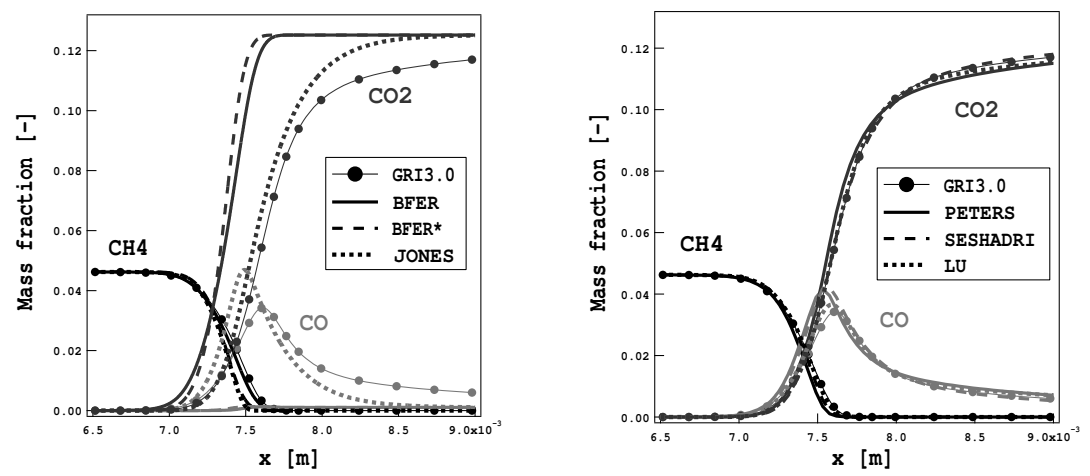

Figure 2. $\mathrm{CH}_{4}, \mathrm{CO}_{2}$ and $\mathrm{CO}$ spatial profiles for $\phi=0.83, T_{f}=320 \mathrm{~K}$ and $P=1 \mathrm{~atm}$. Detail of the reaction zone.

into $\mathrm{CO}_{2}$ in the recombination region. The two-step schemes predict an unphysical monotonous profile and greatly underestimate its maximum value. The value at equilibrium is however correctly described. The JONES results are in good agreement with the detailed mechanism, with a reasonable maximum level although the equilibrium in the post flame region is reached too quickly. The analytical mechanisms predict almost perfectly the flame structure: the maximum level of $\mathrm{CO}$ species is well captured and the equilibrium is reached slowly, as predicted by the GRI3.0 scheme.

\subsection{Results on premixed counterflow flames}

The response to strain rate is evaluated for all reduced mechanisms on classical strained one-dimensional premixed flames (Fig. 3a). A fresh premixed methane/air mixture is injected at $T_{f}=320 \mathrm{~K}$ and $\phi=0.83$ on the left side and combustion products are injected on the right side. The strain rate $a$ is evaluated in the reaction zone identified by an isoline of the progress variable based on $\mathrm{O}_{2}$ species and equal to $c=0.65$ :

$$
a=\frac{\partial v}{\partial y} .
$$

As the mass flow rate increases, the flame is more strained by the velocity field, making the flame front generally thinner and modifying its structure. The response of the mechanisms to strain rate is evaluated in terms of the consumption speed $S_{C}$ (Fig. 3b):

$$
S_{C}=\frac{1}{\rho^{f} Y_{\mathrm{O}_{2}}^{f}} \int \dot{\omega}_{\mathrm{O}_{2}} d x,
$$

where $\rho^{f}$ is the fresh gas density, $Y_{\mathrm{O}_{2}}^{f}$ is the mass fraction of $\mathrm{O}_{2}$ in the fresh gases and $\dot{\omega}_{\mathrm{O}_{2}}$ is the consumption rate of species $\mathrm{O}_{2}$.

From the results of the detailed GRI3.0 mechanism, the consumption speed is expected to decrease when the strain rate increases. This behavior is not correctly reproduced by all schemes: the JONES mechanism shows the opposite tendency, i.e. the consumption speed increases with the strain rate; the 2S_CH4_BFER scheme is not sufficiently affected by the strain rate and too high values of consumption speed are found even for really high strain rates. On the contrary, the modified two-step 2S_CH4_BFER ${ }^{*}$ mechanism shows a great improvement compared to the 2S_CH4_BFER scheme and the agreement with the GRI3.0 mechanism is now satisfactory. The PETERS mechanism is too much affected by strain rate and for high strain rate values the flame quenches. The response to strain rate in terms of consumption 
speed is better predicted by the SESHADRI mechanism, at least for relatively small strain rates, and the LU scheme.

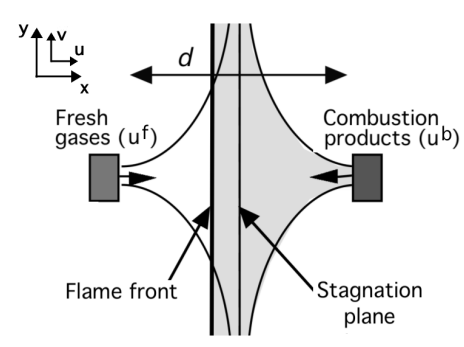

a.

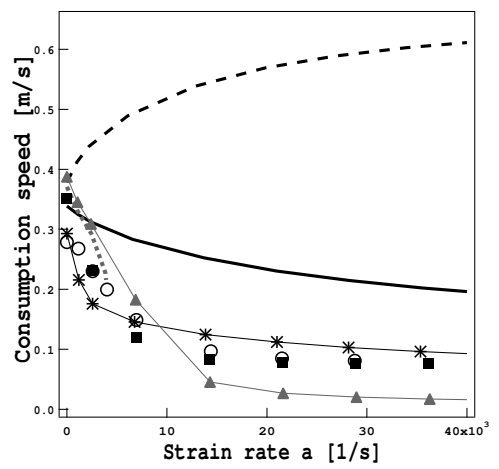

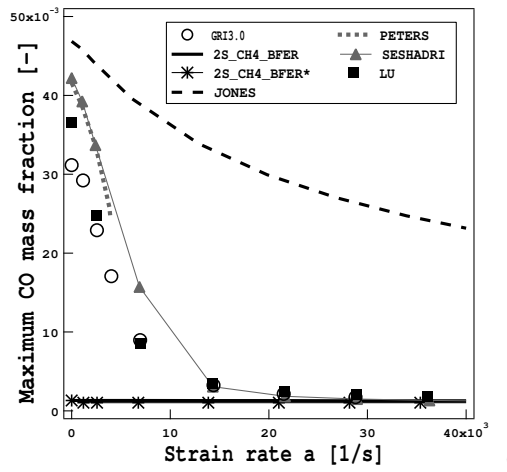

Figure 3. a) Sketch of a premixed strained counterflow flame. b) Consumption speed and c) maximum value of the CO mass fraction for a premixed strained methane/air flame as a function of local strain rate at $T_{f}=320 \mathrm{~K}$. Comparison between the reduced mechanisms and the GRI3.0 detailed scheme.

The maximum value of $\mathrm{CO}$ mass fraction, corresponding to $c=0.65$, is also studied as function of strain rate (Fig. 3c). It is a good indication of the impact of strain rate on the flame structure since intermediate species and radicals are more affected by strain than reactants and products. The two-step mechanisms being unable to predict the $\mathrm{CO}$ concentration in the reaction zone for unstrained flames, the response to strain rate in terms of $\mathrm{CO}$ mass fraction is completely lost. All other mechanisms show the same tendency, when the strain rate increases the $C O$ mass fraction in the reaction zone decreases. More specifically, the JONES scheme overestimates the CO mass fraction in the reaction zone and this error increases with strain rate. The maximum value of $C O$ is on the other hand correctly predicted by the PETERS mechanism, at least for low strain rates, and by the SESHADRI and LU schemes for the whole range of strain rates compared to results of the GRI3.0 scheme.

Globally, it has been observed that the more complex the mechanism is the higher is the accuracy of results on laminar flames and not all schemes correctly respond to strain in terms of consumption speed (2S_CH4_BFER and JONES) or CO mass fraction (2S_CH4_BFER, 2S_CH4_BFER ${ }^{*}$ and JONES). A good description of laminar freely propagating flames is suspected not to be sufficient to correctly describe a turbulent flame. More specifically, the turbulent flame structure is expected to strongly depend on the capability of a mechanism to predict the recombination zone and the intermediate species concentrations, strongly affected by strain, on laminar strained flames. Moreover, the turbulent flame length is supposed to depend on the response to strain of the consumption rate and, as a consequence, the consumption speed $S_{C}$ has to be correctly reproduced on laminar strained flames. The impact of the result discrepancies on laminar strained flames is evaluated on LES of the PRECCINSTA burner in Section 3.

\section{LES of the PRECCINSTA burner}

\subsection{Experimental and numerical setup}

The target experimental burner has been specifically designed to study the impact of partially premixed mixture in flame stability [19]. As sketched in Fig. 4a, air is injected into the plenum through one large 
intake while methane is injected through twelve small tubes of diameter $1 \mathrm{~mm}$ directly into the swirler. Methane and air are then mixed by the high momentum flow of the swirler and a methane/air mixture enters the combustion chamber. The flow in the chamber is characterized by an inner recirculation zone (IRZ) and two outer recirculation zones (ORZ), which enables to stabilize a swirled flame with a classical conical shape at the nozzle exit. The burnt gases finally exit the chamber through the exhaust tube. Two regimes have been experimentally observed, depending on the global equivalence ratio. For $\phi=0.7$, the flame is pulsating where for $\phi=0.83$ the flame keeps stable. Laser Raman scattering
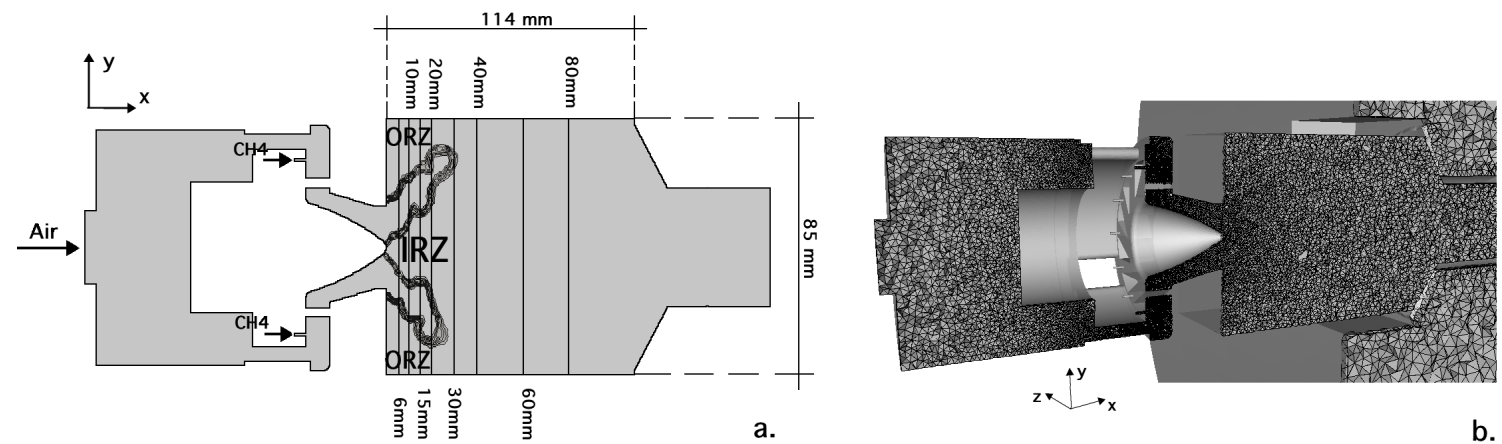

Figure 4. a) Visualization of the experimental PRECCINSTA burner [19]. Isolines of heat release identify the reaction zone. c) Computational half-domain. Mesh comprises about 5 millions of tetrahedral cells.

measurements are available for concentration of the major species $\left(\mathrm{CH}_{4}, \mathrm{CO}, \mathrm{CO}_{2}, \mathrm{H}_{2} \mathrm{O}, \mathrm{H}_{2}, \mathrm{~N}_{2}\right.$ and $\left.\mathrm{O}_{2}\right)$ and for temperature in vertical planes $(y, z)$ at eight different axial positions downstream of the injector ( $h=6,10,15,20,30,40,60,80 \mathrm{~mm}$, where $h=0 \mathrm{~mm}$ corresponds to the exit plane of the nozzle) for at least five radial positions $r$ (Fig. $4 \mathrm{~b}$ ). The systematic and statistical uncertainties are less than $4 \%$ and $2.5 \%$ respectively for temperature and less than $5 \%$ and $7 \%$ respectively for almost all species except for $\mathrm{CO}$ and $H_{2}$ for which statistical uncertainty is between $20-50 \%$ [19].

Numerous simulations have been performed $[24,25,26,27,28]$ assuming a perfect mixing between methane and air at the nozzle exit, which simplifies the computational work. Only recently, fuel/air mixing has been explicitly computed including fuel jets into the swirler in order to estimate the impact of the perfect premixing assumption on thermo-acoustic instabilities [12].

In this work, LES are performed without the perfect mixing assumption on the same unstructured mesh shown in Fig. 4b. Dry air and pure methane are injected separately at ambient temperature $\left(T_{f}=320 \mathrm{~K}\right)$ with air mass flow $\dot{m}_{\text {air }}=734.2 \mathrm{~g} / \mathrm{min}$ and methane mass flow $\dot{m}_{\mathrm{CH}_{4}}=35.9 \mathrm{~g} / \mathrm{min}$, corresponding to the stable operating point $(\phi=0.83)$. The numerical setup proposed in [12] has been used to perform all computations to guarantee consistent comparisons of the results and to correctly identify the impact of the reduced chemical mechanisms. A Taylor-Galerkin weighted residual central distributions scheme is used for numerical integration [29]. The interaction between chemistry and turbulence is modeled by the Dynamically Thickened Flame (DTFLES) model [30]. The sensor activating the flame thickening is based on the net production rate of $\mathrm{CO}$ and $\mathrm{CO}_{2}$ species, which guarantees an equivalent thickening for all chemistries in both the reaction and the post-flame zones. The behavior of the DTFLES model and its sensor has been verified on laminar unstrained flames for the six reduced mechanisms. The inlets for methane and air and the outlet are described by Navier-Stokes Characteristic Boundary Conditions (NSCBC) [31] to ensure a physical representation of the acoustic wave propagation and reflection. An adiabatic no-slip condition is applied to the walls. 


\subsection{Analysis of results}

In Section 2, the GRI3.0 detailed mechanism has been used as the reference and the LU analytical scheme has shown very good agreements with it on the studied laminar configurations. As using the GRI3.0 mechanism to perform LES in the target burner is computationally too expensive, the LU scheme is used as the reference in the following. When analyzing the results, the LU scheme is first compared to the experiments before comparing the performances of the other five mechanisms to the LU results. Figure 5 compares the mean temperature profiles in the vertical mid-plane cut. In Fig. 5.a, the comparison
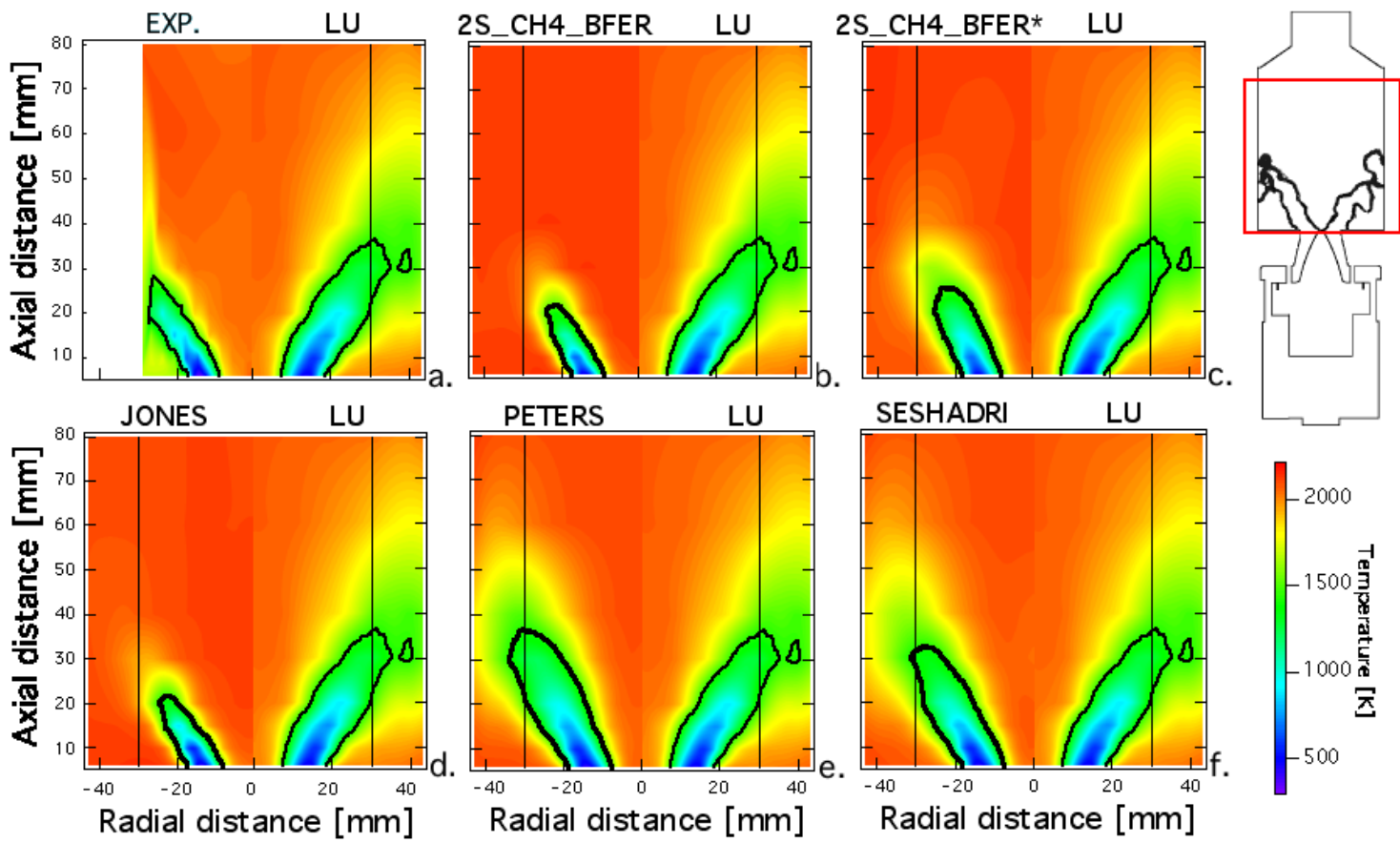

Figure 5. Mean temperature field in the vertical mid-plane. a) Comparison between experiments and LU scheme. b-f) Comparison between reduced schemes and reference LU mechanism. The black iso-line of progress variable $c=0.65$ represents the mean flame surface position.

between experiments and the LU results shows good agreement. The discrepancies are likely to be due to some numerical simplifications, such as combustion model, numerical discretization and adiabaticity assumption. Indeed evaluating the temperature both on the ORZ and in the near wall region is inaccurate when neglecting wall heat losses and radiation effects.

Figures 5.b-5.f compare the LU mechanism with the five other mechanisms. Although the overall agreement is acceptable, the chemical models show non-negligible discrepancies. As already said, the flame length is expected to be related to the consumption rate of the reactants, i.e. the consumption speed $S_{C}$. The higher the consumption speed, the quicker the reactants are burnt and consequently the shorter the flame is. The flames predicted by the 2S_CH4_BFER and the JONES mechanisms confirm the results of the laminar counterflow flames where both schemes overestimate $S_{C}$. As expected, the modified 2S_CH4_BFER* scheme predicts a longer flame than the 2S_CH4_BFER mechanism. The analytical schemes reproduce a correct flame length. Discrepancies are detected also for the post flame region. The 2S_CH4_BFER flame reaches rapidly the equilibrium state in agreement with results for laminar freely propagating flames, whereas a recombination zone touching the wall downstream of the flame $(-40 \mathrm{~mm}<r<-30 \mathrm{~mm}$ and 
$25 \mathrm{~mm}<h<50 \mathrm{~mm}$ ) is detected when using analytical schemes. Globally, the flame structure strongly depends on the chemical description used.

Figures 6 and 7 display the mean and fluctuating profiles at five sections $(h=6,10,20,30$ and $60 \mathrm{~mm})$ in terms of temperature and $C O$ mass fraction. The experiments [19] and the LU results are compared to the results obtained with the five other mechanisms. For the sake of clarity, the 2S_CH4_BFER,2S_CH4_BFER* and JONES results are displayed at the top in black whereas the analytical schemes (PETERS and SESHADRI) are shown at the bottom in grey.
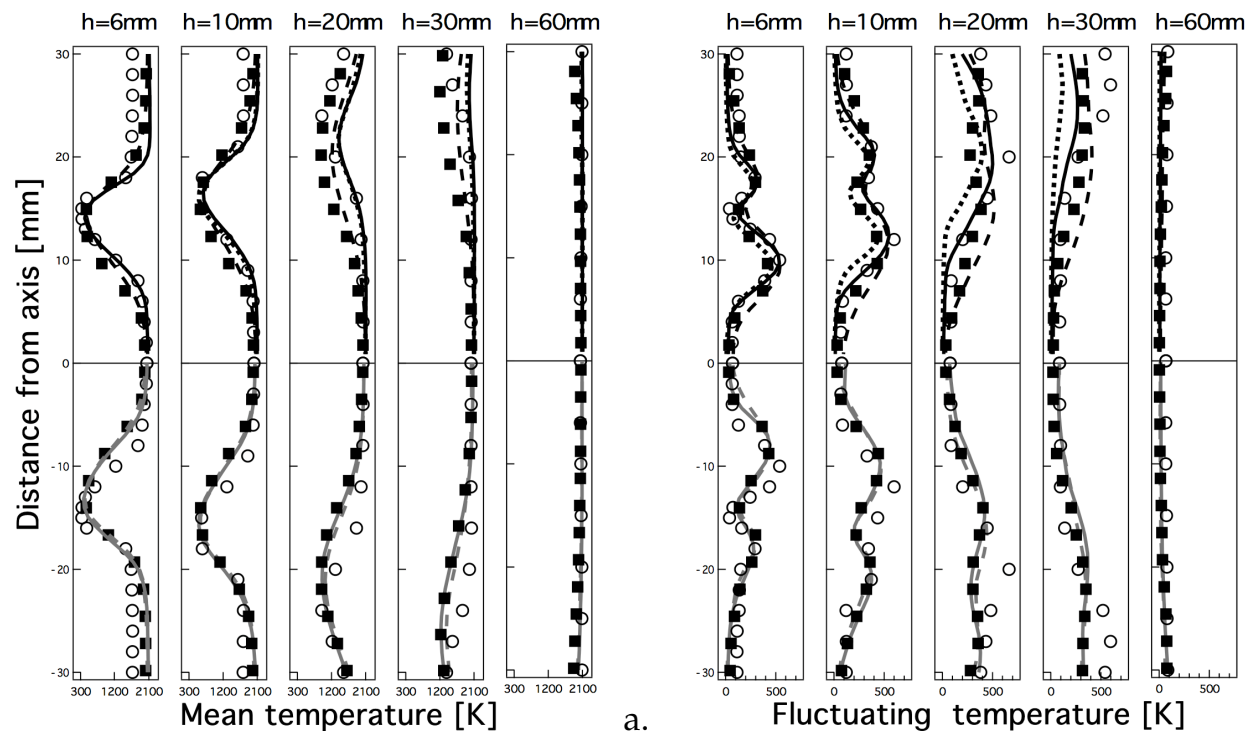

a.

Fluctuating temperature $[\mathrm{K}]{ }^{500} \mathrm{~b}$.

Figure 6. a) Mean and b) fluctuating temperature profiles at five sections in the chamber. The experimental (o) and LU ( $\mathbf{\square})$ results are compared to numerical data for the other mechanisms: top) 2S_CH4_BFER (-), 2S_CH4_BFER*(- - ) and JONES (…); bottom) PETERS ( - ) and SESHADRI ( --$)$.

Concerning the mean and fluctuating temperature profiles (Figs. 6a. and 6b. respectively) the overall agreement is satisfactory. However there are some discrepancies between experimental data and LU results: the underestimation of the IRZ extension at $h=10 \mathrm{~mm}$ and $h=20 \mathrm{~mm}$, as well as the overestimation of the temperature in the ORZ that could be due to wall heat losses and radiation effects which are neglected. The temperature fluctuations are slightly underestimated but the global behavior is well captured. On the one side, results obtained with the analytical mechanisms are in good agreement with the LU results showing that these two schemes could be used instead of the LU mechanism to reduce the computational cost. On the other side, larger discrepancies are detected when using the fitted schemes which overestimate the mean temperature in the layer between the fresh gases and the ORZ $(x>20 \mathrm{~mm}$ at $h=20 \mathrm{~mm})$. Since a smaller flame is predicted by the 2S_CH4_BFER and JONES schemes, the equilibrium temperature is already reached in this region contrary to the experiments. The modified 2S_CH4_BFER* scheme behaves better than the original scheme but discrepancies are still visible. The results for mean and fluctuating profiles of major species $\left(\mathrm{CH}_{4}\right.$ and $\mathrm{CO}_{2}$ for example) present the same characteristics and are not shown in this paper.

In Fig. 7, the mean and fluctuating profiles of $\mathrm{CO}$ species predicted by the five mechanisms are compared to the measurements (note that the experimental error on $\mathrm{CO}$ was estimated at $50 \%$ ) and the LU results. Results are in agreement with the behavior of mechanisms in laminar strained flames (Section 2.3). The simplest 2S_CH4_BFER and 2S_CH4_BFER* schemes greatly underestimate the CO mass fraction in the reaction zone but recover the correct level at equilibrium $(h=60 \mathrm{~mm})$. On the contrary, the JONES 

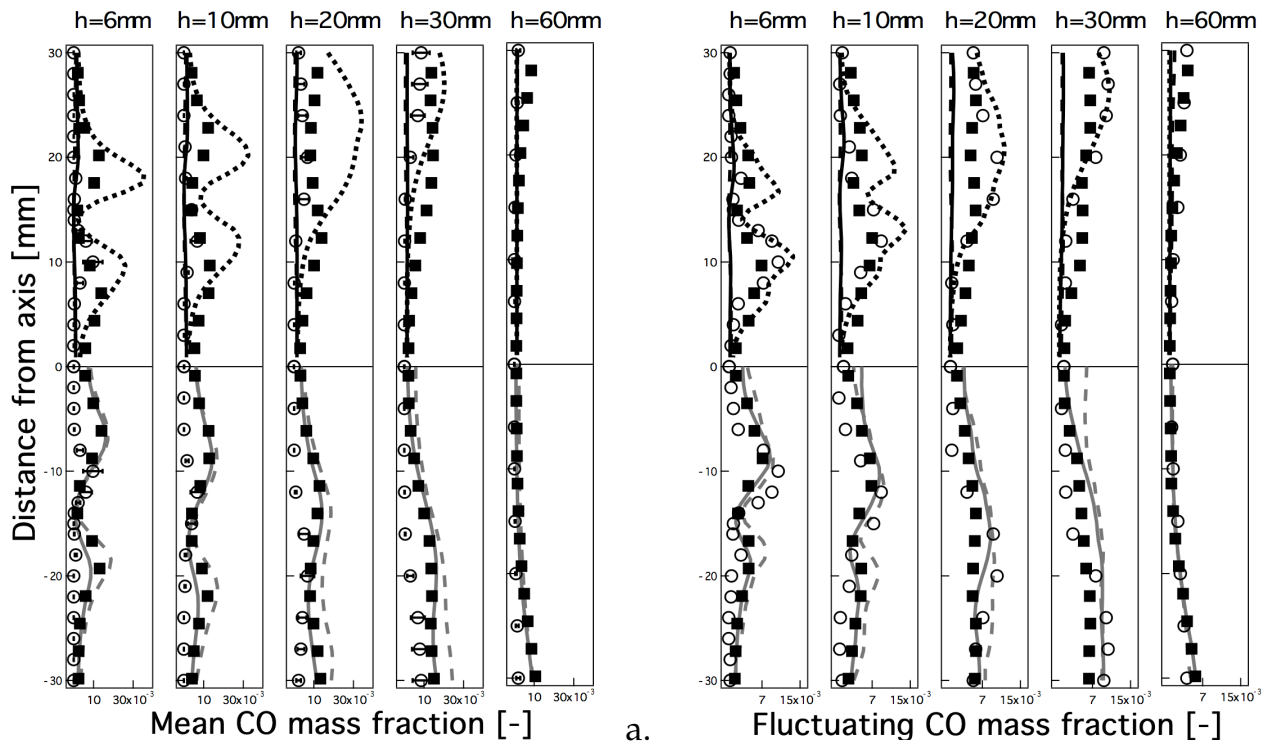

a.

Fluctuating $\mathrm{CO}$ mass fraction $[-]^{75 \times 10^{15}}$ b.

Figure 7. a) Mean and b) fluctuating CO profiles at five sections in the chamber. The experimental (o) and LU ( $\mathbf{\square})$ results are compared to numerical results: top) 2S_CH4_BFER $(-)$, 2S_CH4_BFER* $(\boldsymbol{-}-)$ and JONES (….); bottom) PETERS (- ) and SESHADRI $(--)$.

mechanism greatly overestimates the maximum value of mean and fluctuating $C O$ mass fractions in the reaction zone as expected from the laminar analysis. Only the analytical schemes (PETERS, SESHADRI) correctly predict the $\mathrm{CO}$ mass fraction although the mean and fluctuating values are slightly overestimated in the IRZ. Moreover, only one peak of $C O$ is experimentally detected in the layer between fresh gases and IRZ whereas a smaller second peak of $C O$ is predicted by the analytical schemes, also pointed out by the LU mechanism. The adiabacity assumption and the mesh refinement could be at the origin of this discrepancy.

\section{Conclusion}

In this work the impact of using reduced chemical mechanisms in LES of a three-dimensional partially premixed flame has been analyzed. The origin of the discrepancies between the different simulations has been identified in the performances of these mechanisms on unstrained and strained premixed flames. Even if using reduced mechanisms decreases the computational cost compared to the reference LU calculation (Table 2), it could affect the results quality.

Six reduced chemical schemes for methane-air flames have been first tested in academic configurations of one-dimensional premixed freely propagating and strained counterflow flames. Results have been analyzed by comparison with the GRI3.0 detailed scheme in terms of laminar flame speed and burnt gas temperature as well as the response to strain. The 2S_CH4_BFER scheme has the lowest computational cost but it shows a non-physical behavior for $C O$ and almost no response to strain. This second point can be modified (2S_CH4_BFER*) changing the Lewis numbers without any additional cost. No major improvements are obtained when using the JONES mechanism for an higher computational cost, except a correct description of the flame structure only for unstrained flames. The analytical schemes (PETERS and SESHADRI) accurately predict the consumption speed, the concentration of intermediate species 
and the flame structure for a reduced computational cost of about $20 \%$ compared to the LU scheme.

These behaviors have then been confirmed in the LES of a 3D partially premixed flame at ambient temperature and atmospheric pressure. These results on both academic and industrial configurations allow to propose a methodology to evaluate the capability of a mechanism to predict some threedimensional chemical phenomena basing on one-dimensional unstrained and strained laminar flames configurations:

- an accurate description of the consumption speed for laminar strained flames is necessary to correctly reproduce the length and surface of a turbulent flame;

- to predict the $C O$ concentration in turbulent flames, the $C O$ mass fraction in the reaction zone for unstrained and strained flames must be correctly described;

- the presence of a recombination zone for an unstrained flame guarantees the presence of a small temperature gradient region characterized by product formation in a turbulent configuration.

This methodology allows to a priori choose a chemical scheme depending both on the quality of the results required and the computational cost affordable. It has been however evaluated only on premixed flames and still needs validation for diffusion flames and more specific combustion phenomena such as auto-ignition or flame extinction.

\section{Acknowledgements}

This research project has been supported by a Marie Curie Early Stage Research Training Fellowship of the European Community's Sixth Framework Programme under contract number MEST-CT-2005020426. This work was granted access to the HPC resources of CINES under the allocation 2010-025031 made by GENCI (Grand Equipement National de Calcul Intensif).

\section{References}

[1] R. Hilbert, F. Tap, H. El-Rabii, D. Thévenin, Impact of detailed chemistry and transport models on turbulent combustion simulations, Prog. Energy Comb. Sci 30 (1) (2004) 61-117.

[2] J. Simmie, Detailed chemical kinetic models for the combustion of hydrocarbon fuels, Prog. Energy Comb. Sci. 29 (6) (2003) 599-634.

[3] C. Westbrook, F. Dryer, Simplified reaction mechanisms for the oxidation of hydrocarbon fuels in flames, Combust. Sci. Tech. 27 (1-2) (1981) 31-43.

[4] J. Y. Chen, T. Kaiser, W. Kollmann, Transient behavior of simplified reaction mechanisms for methane nonpremixed combustion, Combust. Sci. Tech. 92 (1993) 313-347.

[5] P. Boivin, C. Jiménez, A. L. Sanchez, F. A. Williams, An explicit reduced mechanism for H2-air combustion, Proc. Combust. Inst. 33 (1) (2011) 517-523.

[6] U. Maas, S. B. Pope, Simplifying chemical kinetics: Intrinsic low-dimensional manifolds in composition space, Combust. Flame 88 (3-4) (1992) 239-264.

[7] O. Gicquel, N. Darabiha, D. Thévenin, Laminar premixed hydrogen/air counterflow flame simulations using flame prolongation of ILDM with differential diffusion, Proc. Combust. Inst. 28 (2) (2000) 1901-1908.

[8] J. A. van Oijen, F. A. Lammers, L. P. H. de Goey, Modeling of complex premixed burner systems by using flamelet-generated manifolds, Combust. Flame 127 (3) (2001) 2124-2134.

[9] R. R. Cao, S. B. Pope, Turbulent lifted flames in a vitiated coflow investigated using joint PDF calculations, Combust. Flame 142 (4) (2005) 438-453.

[10] A. Triantafyllidis, E. Mastorakos, R. L. G. M. Eggels, Large Eddy Simulations of forced ignition of a non-premixed bluff-body methane flame with Conditional Moment Closure, Combust. Flame 156 (12) (2009), pp. 2328-2345.

[11] A. Roux, L. Y. M. Gicquel, S. Reichstadt, N. Bertier, G. Staffelbach, F. Vuillot, T. Poinsot, Analysis of unsteady reacting flows and impact of chemistry description in Large Eddy Simulations of side-dump ramjet combustors, Combust. Flame 157 (1) (2010) 176-191.

[12] B. Franzelli, E. Riber, L. Y. Gicquel, T. Poinsot, Large Eddy Simulation of combustion instabilities in a lean partially premixed swirled flame, Combust. Flame 159 (2012) 621-637. 
[13] W. P. Jones, R. P. Lindstedt, Global reaction schemes for hydrocarbon combustion, Combust. Flame 73 (3) (1988) $233-249$.

[14] N. Peters, Numerical and asymptotic analysis of systematically reduced reaction schemes for hydrocarbon flames, in: R. Glowinsky, B. Larrouturou, R. Temam (Eds.), Numerical simulation of combustion phenomena, Vol. 241, Springer-Verlag, Berlin, 1985 90-109.

[15] K. Seshadri, N. Peters, Workshop on Reduced Kinetic Mechanism and Asymptotic Approximations for Methane-Air Flames, La Jolla, California, 1989.

[16] J. Y. Chen, R. W. Dibble, Applications of reduced chemical mechanisms for the prediction of turbulent nonpremixed methane jet flames, in: M. D. Smooke (Ed.), Reduced Chemical Mechanisms and Asymptotic Approximations for Methane-Air Flames, Vol. 384, Springer-Verlag, New York, 1991 193-226.

[17] T. Lu, C. K. Law, A criterion based on computational singular perturbation for the identification of quasi steady state species: A reduced mechanism for methane oxidation with NO chemistry, Combust. Flame 154 (4) (2008) 761-774.

[18] R. Sankaran, E. R. Hawkes, J. H. Chen, T. Lu, C. K. Law, Structure of a spatially developing turbulent lean methane-air Bunsen flame. Proc. Combust. Inst. 31, 2007 1291-1298.

[19] W. Meier, P. Weigand, X. R. Duan, R. Giezendanner-Thoben, Detailed characterization of the dynamics of thermoacoustic pulsations in a lean premixed swirl flame, Combust. Flame 150 (1-2) (2007) 2-26.

[20] B. Franzelli, E. Riber, M. Sanjosé, T. Poinsot, A two-step chemical scheme for kerosene-air premixed flames, Combust. Flame 157 (7) (2010) 1364-1373.

[21] T. Poinsot, D. Veynante, Theoretical and Numerical Combustion, R.T. Edwards, 2nd edition, 2005.

[22] F. Frenklach, H. Wang, C. L. Yu, M. Goldenberg, C. T. Bowman, R. K. Hanson, D. F. Davidson, E. J. Chang, G. P. Smith, D. M. Golden, W. C. Gardiner, V. Lissianski, http://www.me.berkeley.edu/gri_mech.

[23] D. G. Goodwin, Cantera C++ Users Guide, http://sourceforge.net/projects/cantera (2002).

[24] S. Roux, G. Lartigue, T. Poinsot, U. Meier, C. Bérat, Studies of mean and unsteady flow in a swirled combustor using experiments, acoustic analysis, and large eddy simulations, Combust. Flame 141 (1-2) (2005) 40-54.

[25] J. Galpin, A. Naudin, L. Vervisch, C. Angelberger, O. Colin, P. Domingo, Large-eddy simulation of a fuel-lean premixed turbulent swirl-burner, Combust. Flame 155 (1-2) (2008) 247-266.

[26] G. Albouze, L. Gicquel, T. Poinsot, Chemical kinetics modeling and LES combustion model effects on a perfectly premixed burner, C. R. Mécanique 337 (6-7)(2009) 318-328.

[27] B. Fiorina, R. Vicquelin, P. Auzillon, N. Darabiha, O. Gicquel, D. Veynante, A filtered tabulated chemistry model for LES of premixed combustion, Combust. Flame 157 (3) (2010) 465-475.

[28] V. Moureau, P. Domingo, L. Vervisch, From Large-Eddy Simulation to Direct Numerical Simulation of a lean premixed swirl flame: Filtered laminar flame-PDF modeling, Combust. Flame 158 (7) (2011) 1340-1357.

[29] V. Moureau, G. Lartigue, Y. Sommerer, C. Angelberger, O. Colin, T. Poinsot, Numerical methods for unsteady compressible multi-component reacting flows on fixed and moving grids, J. Comput. Phys. 202 (2) (2005) 710-736.

[30] O. Colin, F. Ducros, D. Veynante, T. Poinsot, A thickened flame model for large eddy simulations of turbulent premixed combustion, Phys. Fluids 12 (7) (2000) 1843-1863.

[31] T. Poinsot, S. Lele, Boundary conditions for direct simulations of compressible viscous flows, J. Comput. Phys. 101 (1) (1992) 104-129.

\section{Tables}

Table 1

Species Lewis numbers.

\begin{tabular}{|c|c|c|c|c|c|c|c|c|}
\hline Scheme & $\mathrm{CH}_{4} \mathrm{O}_{2} \mathrm{CO}_{2} \mathrm{CO} \mathrm{H} \mathrm{H}_{2} \mathrm{OH}_{2}$ & $\mathrm{H}_{2} \quad \mathrm{~N}_{2}$ & $H$ & $O$ & $\mathrm{OH}$ & $\mathrm{HO}_{2}$ & $\mathrm{CH}_{3} \mathrm{C}$ & $\mathrm{CH}_{2} \mathrm{O}$ \\
\hline 2S_CH4_BFER & 1.001 .001 .001 .001 .00 & -1.00 & - & - & - & - & - & - \\
\hline 2S_CH4_B & 1.651 .651 .6 & 1.65 & - & - & 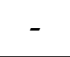 & 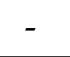 & & - \\
\hline Others & 0.971 .061 .351 .070 .780 .2 & 291.04 & 0.17 & 0.69 & 0.7 & 1.07 & 0.97 & 1.25 \\
\hline
\end{tabular}

Table 2

Computational time normalized by the computation time of the LES using the LU scheme.

\begin{tabular}{cccccc}
\hline 2S_CH4_BFER 2S_CH4_BFER* & JONES PETERS SESHADRI LU \\
\hline 0.72 & 0.72 & 0.79 & 0.81 & 0.81 & 1.00
\end{tabular}

